\begin{tabular}{|c|c|}
\hline Title & A Sign-Logo Image Search \& Combination System by Analyzing Color and Shape Features \\
\hline \multicolumn{2}{|l|}{ Sub Title } \\
\hline Author & $\begin{array}{l}\text { 豊島, 有紀(Toyoshima, Yuki) } \\
\text { 林, 康弘(Hayashi, Yasuhiro) } \\
\text { 清木, 康(Kiyoki, Yasushi) }\end{array}$ \\
\hline Publisher & 慶應義塾大学湘南藤沢学会 \\
\hline Publication year & 2012 \\
\hline Jtitle & 交通運輸情報プロジェクトレビューNo.21 (2012. ) ,p.75- 82 \\
\hline \multicolumn{2}{|l|}{ JaLC DOI } \\
\hline Abstract & $\begin{array}{l}\text { This paper presents a sign-logo search and combination system by analyzing the color and shape } \\
\text { features of sign-logos. The objective of this system is to find a global way of communications by } \\
\text { combining sign-logo images, which are created by combining color and shape features to express } \\
\text { important messages with visualizations. This system analyses the color and shape features of the } \\
\text { image input by a user, also divides the shape into frames and objects, which consist of color } \\
\text { layers. The frame stands for the context of the message, and the objects stand for the target of } \\
\text { the message. The colors used in the sign-logos tend to implicitly express the importance of the } \\
\text { message. The results of several experimentations for evaluating effectiveness of our system are } \\
\text { shown in this paper. }\end{array}$ \\
\hline Notes & $\begin{array}{l}\text { 2012年度慶應義塾大学JR東日本寄附講座報告書 } \\
\text { 慶應義塾大学交通運輸情報プロジェクト } \\
\text { その3:慶應SFCC研究員·院生·学部生の研究 }\end{array}$ \\
\hline Genre & Technical Report \\
\hline URL & $\begin{array}{l}\text { https://koara.lib.keio.ac.jp/xoonips/modules/xoonips/detail.php?koara_id=KO92001006-0000002 } \\
\text { 1-0075 }\end{array}$ \\
\hline
\end{tabular}

慶應義塾大学学術情報リポジトリ(KOARA)に掲載されているコンテンツの著作権は、それぞれの著作者、学会または出版社/発行者に帰属し、その権利は著作権法によって 保護されています。引用にあたっては、著作権法を遵守してご利用ください。

The copyrights of content available on the KeiO Associated Repository of Academic resources (KOARA) belong to the respective authors, academic societies, or publishers/issuers, and these rights are protected by the Japanese Copyright Act. When quoting the content, please follow the Japanese copyright act. 


\title{
A Sign-Logo Image Search \& Combination System by Analyzing Color and Shape Features
}

\author{
YUKI TOYOSHIMA $^{\dagger}$ YASUHIRO HAYASHI ${ }^{\ddagger}$ and YASUSHI KIYOKI ${ }^{\dagger}$ \\ $\uparrow$ Faculty of Environment and Information Studies, Keio University \\ 5322 Endo, Fujisawa, Kanagawa, 252-8520 Japan \\ ‡ Faculty of Photonics Science, Chitose Institute of Science and Technology \\ 758-65, Bibi, Chitose, Hokkaido, 066-8655 Japan \\ E-mail: †\{t09651yt, kiyoki\}@sfc.keio.ac.jp $\quad \ddagger$ yasuhiro@photon.chitose.ac.jp
}

\begin{abstract}
This paper presents a sign-logo search and combination system by analyzing the color and shape features of signlogos. The objective of this system is to find a global way of communications by combining sign-logo images, which are created by combining color and shape features to express important messages with visualizations. This system analyses the color and shape features of the image input by a user, also divides the shape into frames and objects, which consist of color layers. The frame stands for the context of the message, and the objects stand for the target of the message. The colors used in the sign-logos tend to implicitly express the importance of the message. The results of several experimentations for evaluating effectiveness of our system are shown in this paper.
\end{abstract}

\section{Introduction}

Through out the world, there are many kinds of signs and logos used for maintaining our safety and security. The signlogos are representing certain messages, which are created by the sender for receivers to see them. Generally, people can intuitively understand the messages corresponding to intentions of meaning based on color and shape features of sign-logo images. The messages that are expressed by combining of color and shape features are shown in Figure 1, which is based on the United Nations Special Commission Survey [1]. For example, the combination of color (blue) and shape (circle) stands for the meaning (mandatory).
Content Based Image Retrieval (CBIR) systems are normally used to find our similar images to a given query image. These systems help us to find the image we are looking for. The image retrieval has been researched since the 1990s. QBIC [4, 5] released by IBM is a first commercial image retrieval engine. A lot of efficient retrieval engines have developed after that. Google Goggles [3] provided us with image retrieval services on WWW. This system retrieves objects that are included on an image that is taken by mobile phone with a digital camera. Most researches in CBIR have focused on developing concrete retrieval algorithms $[7,8,9,16,19,20,23]$. Image-query creation has been proposed as the one method of dealing with the retriever's intention that should be more considered in CBIR. In this method, the user's intentions that are focused on the image-features on retrieval steps are expressed by combining multiple images $[12,13,14]$

In this paper, we present a sign-logo image search and combination system focusing on the color and shape features of the sign-logos. The objective of this system is to find a global way of communicating by combining sign-logo images, which are created by combining color and shape features to express a certain message. This system analyses the color and shape information of the image input by the user, and divides the shape information into the frame information and object information, which consists of the color layers. The frame stands for the context of the message, and the objects stand for the target of the message. The colors used in the sign-logos tend to implicitly express the importance of the message. The objects consist of some shapes having the same color, and the frame consists. of the outline shape of a main object in the sign-logo image. By 
combining the colors, the frame and the objects that correspond to the message, the sign-logo message becomes visually clear to the receivers. The main feature of this system is to utilize the image retrieval in order to communicate with each other by combining three image features (colors, frames and objects) of sign-logo images based on the user's imagination that he/she imagines. In our system, we have implemented the decomposition and combination functions to search functions that legacy image retrieval systems already have. We have noticed that the image-context can be clearly express by combining multiple image-features. So, our approach connected these functions to create a new way to combine images for realizing a sigh-logo image world.

\begin{tabular}{|c|c|c|c|c|}
\hline Color & Square & Rectangle & Circle & Triangle \\
\hline Red & & & & \\
\hline Yellow & & Prohibition & Regulation \\
\hline Green & & $\begin{array}{c}\text { Ald, } \\
\text { Bive }\end{array}$ & Warning \\
\hline Mandatory & Mandatory & Mandatory & \\
\hline
\end{tabular}

Figure 1. The Messages that Are Expressed by Combining of Color and Shape Features

\section{Basic Method of Sign-Logo Image Search \& Combination System}

In our system, we focus on basic elements of image features the sign-logo has. The basic colors and shape combinations are based on the survey from United Nations Special Commission (Figure 1), and the safety colors from the JIS (Japanese Industrial Standards) and ISO (International Organization for Standardization) regulation (Figure 2). The colors used in this system are 10 colors (red, orange, yellow, green, cyan, blue, purple, magenta, white, black) based on the 8 colors from the JIS safety colors [2] with the additive primary colors (red, green, blue) and subtractive primary colors (magenta, yellow, cyan). Each color of sign-logo images is layered in 10 color layers in this system (Figure 3 ).
The sample images are based on [2] and each image has a certain message (red: do not enter, orange: departure immigration, yellow: taxi, green: emergency exit, blue: information corner, purple: radio activity, white: information center, black: telephone, magenta: baby facility, cyan: directions).

The shapes used in this system are separated to the frame-shape and object-shapes. Primitive shapes (circle, triangles, squares, rectangles, diamond, pentagon, hexagon) are used for the frame as shown in Figure 4. Variations of objects such as the ones shown in Figure 5 are representing the target of sign-logo as the object-shapes used for expressing the message. In this point of view, we point out that all the signs and logos, pictograms, symbol marks, road signs etc. can be considered as the same, and define them as sign-logos. We do not consider letters in logotypes as signlogos, since they directly show letters for reading.

\begin{tabular}{|c|c|c|}
\hline JIS & Color & Meaning \\
\hline & Red & $\begin{array}{l}\text { File Extinction, Prohibition, Stop, } \\
\text { High risk of danger }\end{array}$ \\
\hline & Green & Salety, Evacuation, Health, Aid, Progress \\
\hline & Blue & Mandatory, Precaution \\
\hline & Yellow & Warning \\
\hline & Orange & Danger, Securty facilities for air and sail \\
\hline & Purple & Radiation \\
\hline & White & Passage, Order \\
\hline & Black & Word, Mark \\
\hline
\end{tabular}

Figure 2. The 8 Safety Colors and The Meaning

In order to create a sign-logo message, this system mainly has three processes: (1) Decomposition, (2) Search and (3) Combination. The processes are shown in Figure 6. In the decomposition process, this system decomposes the color, the frame and the objects from the sign-logo image. This system executes frame-level and object-level search in order to retrieve similar sign-logo images in the search process. In the combination process, the system combines the colors, the frame and the objects for creating a new sign-logo 
image. The system has a cycle process from 1 to 3 for refining the meaning of created sign-logo image by analyzing the image.

The system structure is shown in Figure 7. Firstly, the user posts the sign-logo image that actually exists to the system. Then, the script program receives and connects to the image processing methods. The analyzed data from the image processing methods would be responded back to the script program, and then the result information would be shown to the user on the browser interface.

A concrete extraction method of the image features on this system consists of three processes. In the first process, the input sign-logo image is resized by constant width and length size. In the second process, the background of the image is subtracted and saved as the base image used in this system. At the same time, in the third process, another image would be saved, which is filled with the main color of the image. This image becomes the frame image.

The colors used in the base image are clustered by the most similar color of 10 colors; which means reducing the variations of colors. The color histogram $[15,18]$, which contains the color ratio information, is extracted from every pixel of the modified base image. Except for the case of white and black, the colors with smaller ratios compared to the threshold is shifted, and added to the similar color. Based on this shifted color histogram, the system generates the color layer images, which becomes the important images used for decomposing the analyzed data: area (pixels), object count, and centroid ( $x$ and $y$ point) for the whole image. These layers also have the role to separate the image into objects.

The area data means pixel count of each color layer and it is used for judging concentration degree of objects on the same color layer. In this process, the area data holds the position information on each pixel. In the case of each element of color histogram, they don't hold the information. Additionally, if the information on all the area data is integrated, it will become equivalent to the color histogram. The object count means number of objects that exist on each color layer. The centroid means summation of all centroids of each object that exists on each color layer. These values are used for the key for searching objects with a different color and the similar shape.

After the base image, frame images, and object images are generated; these images are analyzed and used for the search process. Furthermore, the image-features are extracted as vector data model, and are stored to tables of the sign-logo image database corresponding to schema of the imagefeatures.

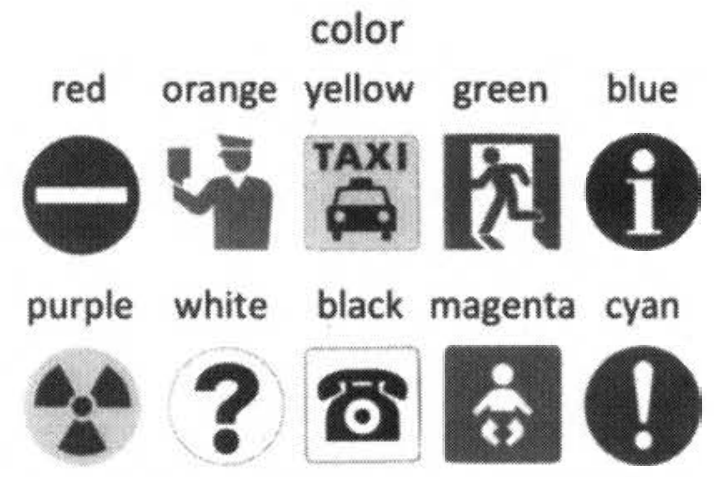

Figure 3. 10 Color Samples in Actual Sign-logo Images

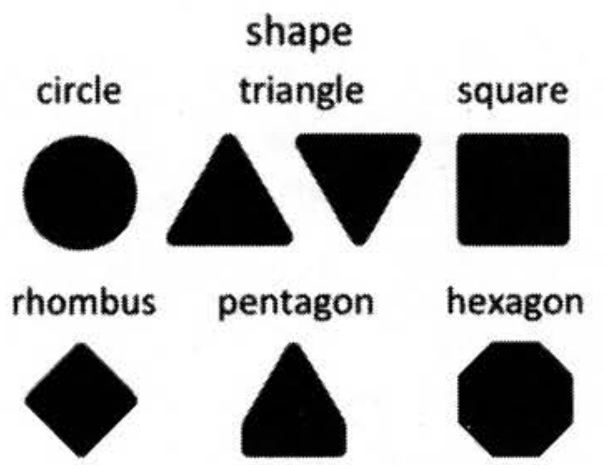

Figure 4. Image Examples Showing The Frame-level Shapes

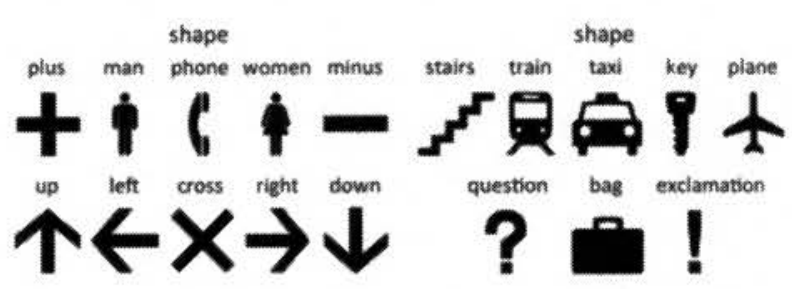

Figure 5. Image Examples Showing The Object-level Shapes

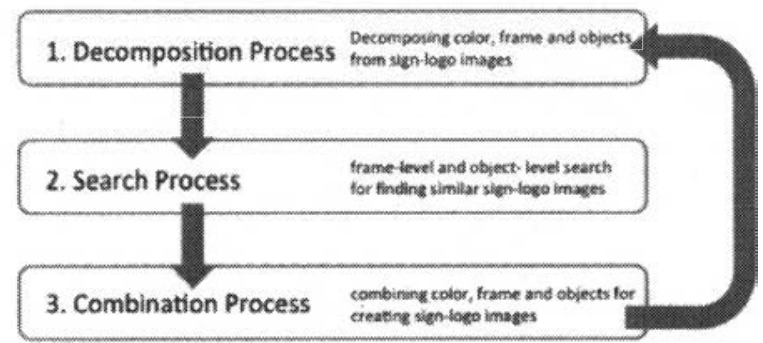

Figure 6. The Three Main Processes of This System 


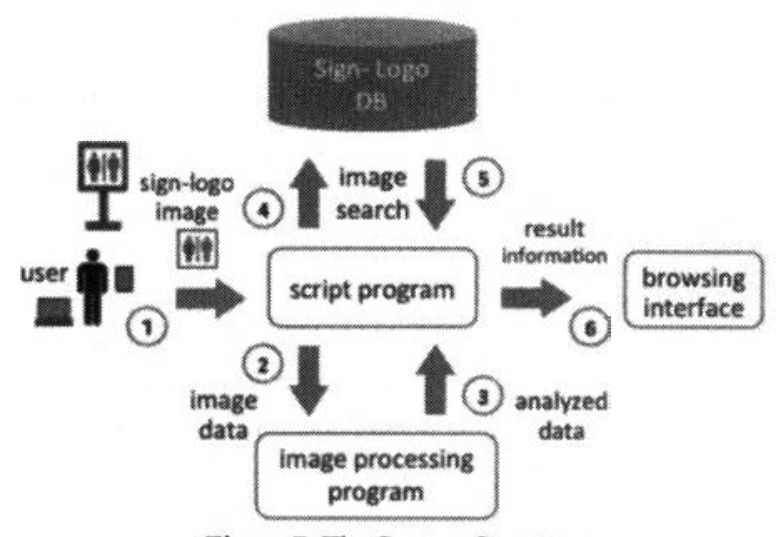

Figure 7. The System Structure

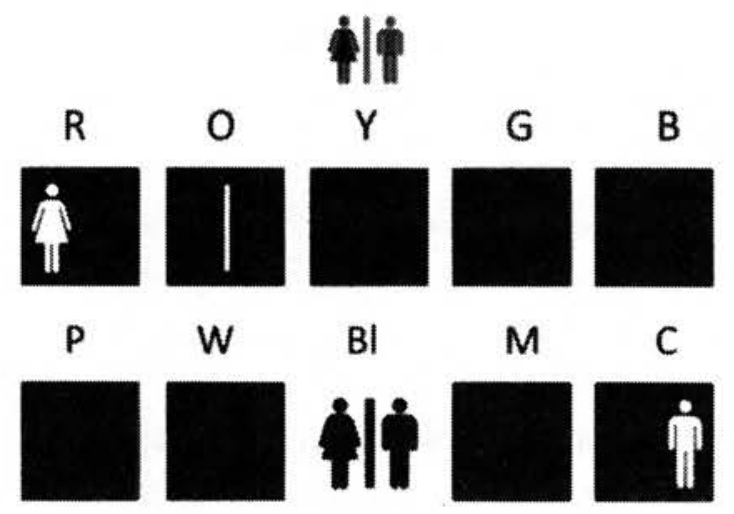

Figure 8. Example of The Decomposition Process

The system uses the analyzed data from the decomposition process in the search section. The data structure of the sign-logo database is shown in Figure 9-12.

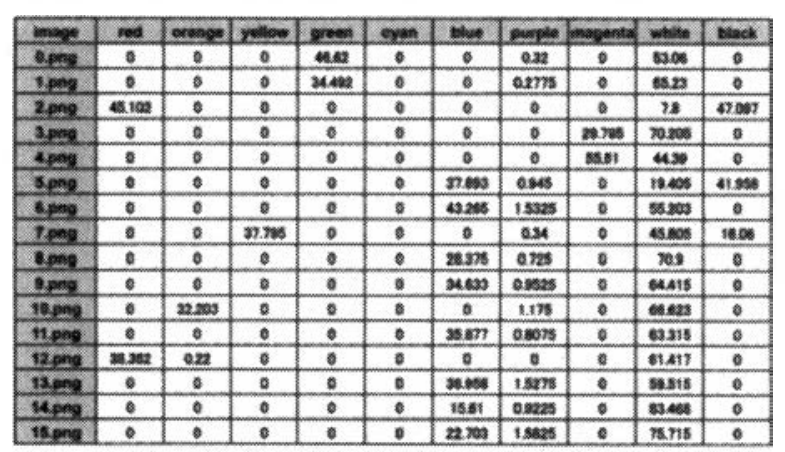

Figure 9. Data Structure of the Color Table

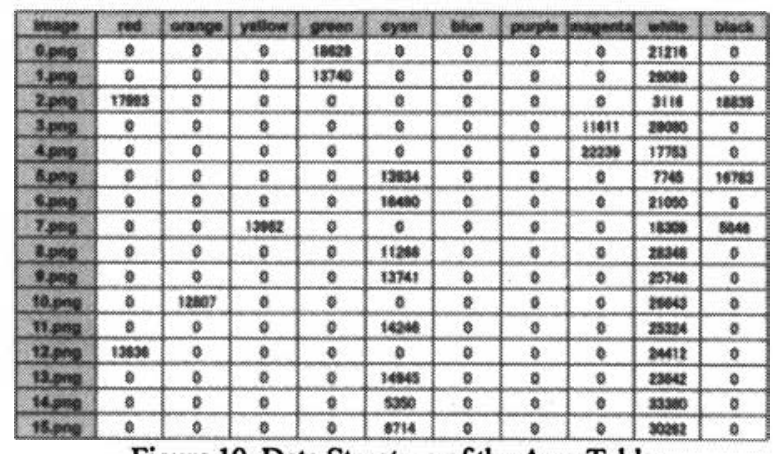

Figure 10. Data Structure of the Area Table

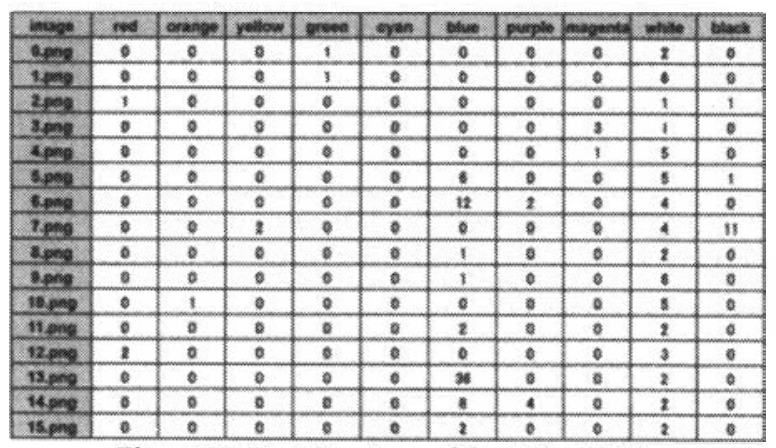

Figure 11. Data Structure of the Object Table

\section{Implementation}

We have implemented an experimental system by applying the MATLAB system [17]. The user interface of the input form and the browsing interface that are shown in Figure 4 were developed by PHP and HTML. All image features of 100 sign-logo images that were extracted by a series of image processing in advance are stored to array as the sign-logo database. Some sign-logo images as examples that are stored to the sign-logo database are shown in Figure 13. These images and text data explaining the meaning of each signlogo image were collected from the World Wide Visual Symbols [2]. Each image stands for a certain message (1: cars do not enter, 2: aid, 3: caution, 4: workers on road, 5: do not run, 6: lost and found, 7: pedestrians crossing, 8: no cars except two wheels, 9: taxi, 10: wheelchair slope based on [2]).

Each RGB value of the 10 representative colors that are defined to the system is as follows: red $=\left[\begin{array}{llll}197 & 14 & 10\end{array}\right]$, orange $=\left[\begin{array}{lll}249 & 103 & 0\end{array}\right]$, yellow $=\left[\begin{array}{lll}255 & 183 & 0\end{array}\right]$, green $=\left[\begin{array}{lll}0 & 118 & 101\end{array}\right]$, blue $=\left[\begin{array}{lll}10 & 87 & 157\end{array}\right]$, purple $=\left[\begin{array}{lll}15660 & 143\end{array}\right]$, white $=\left[\begin{array}{ll}248 & 241\end{array}\right.$ 252], black $=\left[\begin{array}{lll}28 & 2630\end{array}\right]$, magenta $=\left[\begin{array}{lll}201 & 73 & 162\end{array}\right]$, cyan $=[0$ $174239]$. The RGB values of all colors that are defined by 


\begin{tabular}{|c|c|c|c|c|c|c|c|c|c|c|c|c|c|c|c|c|c|c|c|c|}
\hline knage. & $\operatorname{cod} x$ & $\operatorname{red} x$ & brange & brange & Wollow & yollow & green $x$ & green y & $\operatorname{cran} x$ & $\operatorname{cyan} y$ & Blue $x$ & blue $y$ & purples & purples & hegenta & pagenta & while $x$ & If while $y$ & black $x$ & black $y$ \\
\hline epen & 0 & 0 & 0 & 0 & 0 & 0 & 10057 & 100.52 & 0 & 0 & 0 & 0 & 0 & 0 & 0 & 0 & 10041 & 10045 & 0 & \\
\hline $1 . \mathrm{peg}$ & 0 & 0 & 0 & 0 & 0 & 0 & 85513 & 102.41 & 0 & 0 & 0 & 0 & 0 & 0 & 0 & 0 & 10665 & 75.789 & 0 & 0 \\
\hline $2 \mathrm{gen}$ & 10043 & 10044 & 0 & 0 & 0 & 0 & 0 & 0 & 0 & ? & 0 & 0 & 0 & 0 & 0 & 0 & 1005 & 1005 & 100.58 & 100.56 \\
\hline $3 \mathrm{eng}$ & 0 & 0 & 0 & 0 & 0 & 0 & 0 & 0 & 0 & 0 & 0 & 0 & 0 & 0 & 115.27 & 97.30 & 858 & os.m & 0 & 0 \\
\hline $4 p 92$ & 0 & 0 & 0 & 0 & 0 & 0 & 0 & 0 & 0 & 0 & 0 & 0 & 0 & 0 & 10002 & 100.15 & 10028 & 1006 & 0 & 0 \\
\hline 8909 & 0 & 0 & 0 & 0 & 0 & 0 & 0 & 0 & 0 & 0 & 11165 & 61.042 & 0 & 0 & 0 & 0 & 10047 & 13485 & 0201 & 60.439 \\
\hline $6 \mathrm{pen}$ & 0 & 0 & 0 & 0 & 0 & 0 & 0 & 0 & 0 & 0 & 101.28 & sersess & 0 & 0 & 0 & 0 & 1008 & 10831 & 0 & 0 \\
\hline $7 \mathrm{pm}$ & 0 & 0 & 0 & 0 & 10035 & 08057 & 0 & 0 & 0 & 0 & 0 & 0 & 0 & 0 & 0 & 0 & 10051 & 10054 & 20312 & 82393 \\
\hline s.peg. & 0 & 0 & 0 & 0 & 0 & 0 & 0 & 0 & 0 & 0 & 105.04 & 12808 & 0 & 0 & 0 & 0 & 10042 & 2255 & 10 & 0 \\
\hline 2.082 & 0 & 0 & 0 & 0 & 0 & 0 & 0 & 0 & 0 & 0 & 1023 & 101.00 & 0 & 0 & 0 & 0 & 92142 & 74500 & 0 & 0 \\
\hline $10 \mathrm{peg}$ & 0 & 0 & 100.43 & 11027 & 0 & 0 & 0 & 0 & 0 & 0 & 0 & 0 & 0 & 0 & 0 & 0 & 100.28 & 25.18 & 0 & 0 \\
\hline 11.ene & 0 & 0 & a & 0 & 0 & 0 & 0 & 0 & 0 & 0 & 10472 & 12208 & 0 & 0 & 0 & 0 & 1241 & ss.sss & 0 & 0 \\
\hline $12 p 99$ & 96.428 & 10465 & 0 & 0 & 0 & 0 & 0 & 0 & 0 & 0 & 0 & 0 & 0 & 0 & 0 & 0 & 22028 & e.7.79 & 0 & 0 \\
\hline 13.pege & 0 & 0 & 0 & 0 & 0 & 0 & 0 & 0 & 0 & 0 & 97.53 & 82418 & 0 & 0 & 0 & 0 & 10033 & 10032 & 0 & 0 \\
\hline 14.pen & 0 & 0 & 0 & 0 & 0 & 0 & 0 & 0 & 0 & 0 & 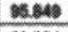 & 25.704 & 0 & 0 & 0 & 0 & 100.43 & 10068 & 0 & 0 \\
\hline $15 \mathrm{pmg}$ & 0 & 0 & 0 & 0 & 0 & 0 & 0 & 0 & 0 & 0 & onses & 9207 & 0 & 0 & 0 & 0 & 9738 & 1000 & 0 & 0 \\
\hline
\end{tabular}

Figure 12. Data Structure of the Centroid Table

JIS and ISO standards are used. Comparing color difference on RGB color space between each color of two pixels is calculated by Euclidean distance.

In this system, the image-features of an image are expressed as vector data. To efficiently calculate similarity degree between two vectors, histogram intersection is adopted to the search step in the system.

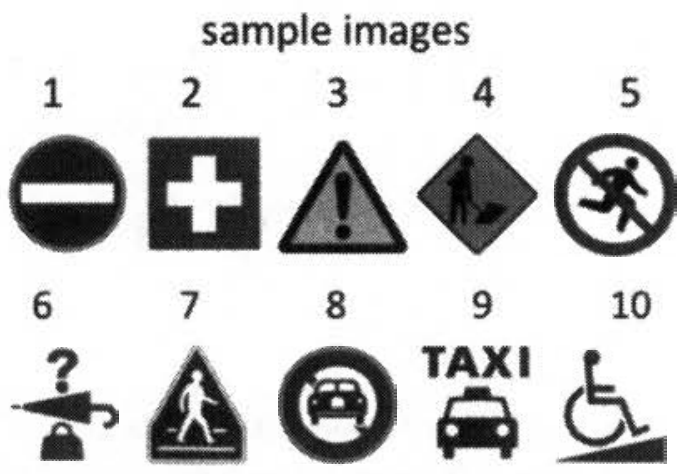

Figure 13. The Sign-Logo Sample Images Stored to the Database

\section{Experiments}

In this time, we have evaluated performance of minimum functions required for whole of the sign-logo search \& combination system through several experiments.

\subsection{Experiment-1}

In Experiment-1, we used 100 sign-logo sample images to check how well the background of the image is erased. The contents of the sign-logo should remain, while the background colors are being removed. The numbers of correctly processed images were 92 , which means $92 \%$ of the images processed in this system returns the correct results.

\subsection{Experiment-2}

In Experiment-2, we checked the color layers for the sample images to see how well the colors are decomposed. Out of the 100 images, $98.7 \%$ of the images were correctly processed and analyzed with correct objects on each layer. The red layers were $99.7 \%$, orange layers were $100 \%$, yellow layers were $100 \%$, green layers were $100 \%$, cyan layers were $99.8 \%$, blue layers were $99.5 \%$, purple layers were $99.9 \%$, magenta layers were $99.8 \%$, and white and black layers were $100 \%$ correct.

\subsection{Experiment-3}

In Experiment-3, we set an image-query (stop sign) and compared with 5 sample images. Firstly, the image-query becomes decomposed as shown in Figure 14.

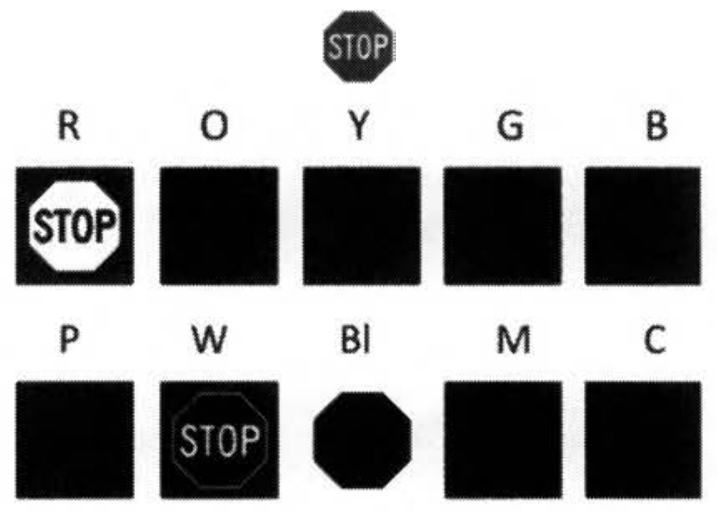

Figure 14. Decomposition Process of The Image-Query 
The 5 sample images are chosen in the similarity level, compared to the image-query. The sample images and the similarity level are shown in Figure 15.

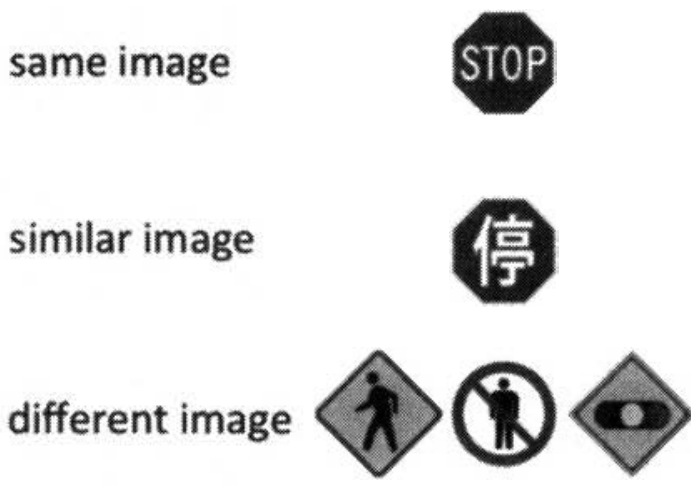

Figure 15. Sample Images and Levels

Next, we calculated the integration between the imagequery and each sample image. The results are ranked as in Figure 16.

\section{STOP}

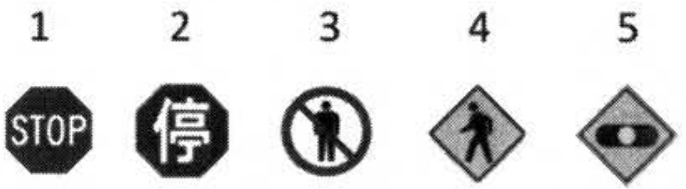

Figure 16. Ranking Results to The Given Image-Query in The Search Process

\subsection{Experiment-4}

For Experiment-4, we set an image-query (toilet) that is more complicated in comparing to Experiment-2, and it is compared to sample images that are also more complicated. The image-query becomes decomposed as shown in Figure 17.

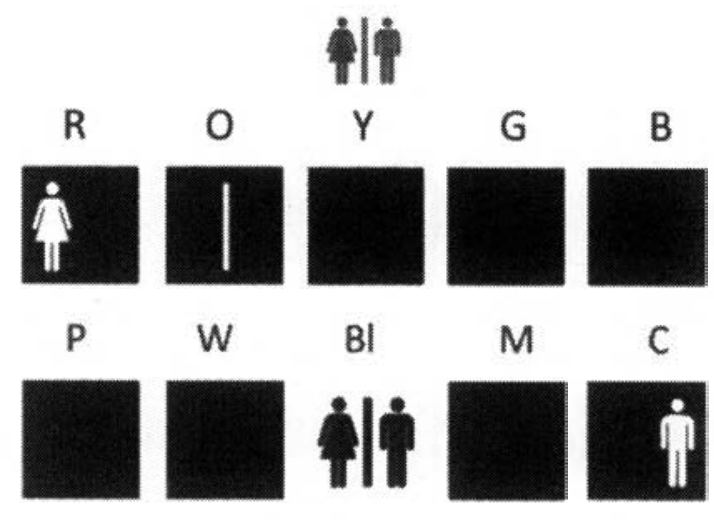

Figure 17. Decomposition Process of The Image-Query

The sample images and the similarity level are shown in Figure 18.

$$
\text { same image }
$$

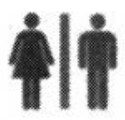

similar image

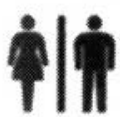

\section{different image}

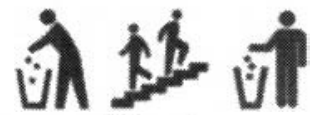

Figure 18. Sample Images and Levels

In the same way as Experiment-3, we succeeded in calculating the integration between the image-query and each sample image. The results are ranked as in Figure 19.

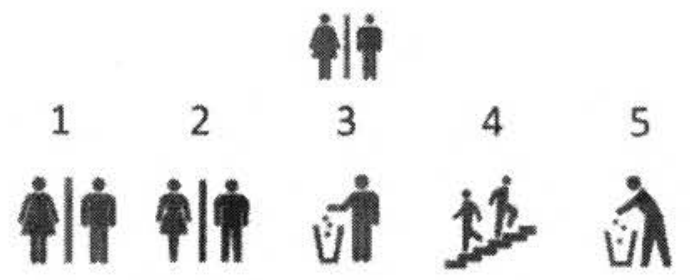

Figure 19. Ranking Results to The Given Image-Query in The Search Process 


\section{Conclusion}

In this paper, we have presented a sign-logo search \& combining system focusing on the color and shape features of sign-logos. This system analyses the color and shape information of the image input by the user, and divides the shape information into the frame information and object information, which consists of the color layers. In order to realize the sign-logo communication, we have experimented to confirm effectiveness of our system. In Experiment-1, we found out that the preprocessing step of the system is $92 \%$ correctly working. The $8 \%$ of the images turned out to be blank because the system misread the color information and erased the necessary colors in the image with the background colors. From Experiment-2, we found out that $98.7 \%$ of the color layers were correctly processed. Almost all the color layers were correctly generated, but the wrong layers tend to turn out as sets for the close colors such as blue and cyan, purple and magenta. From Experiments-3 and 4, by setting the same, similar, and different images in the retrieval step we found out that the same image becomes 1st rank and the similar image becomes 2 nd. From this experiment, we noticed that the decomposition and search process is working. The combining section should be added and connected so that the

As our future work, we have several points we need to cover and extend in order to create a better system and a sophisticated user interface. Firstly, as mentioned in Experiment 2, we need to figure out how to process the close colors correctly. Secondly, in our current system, the objects in the same color layer are counted as one object. In the future, the system needs to be improved so that the related objects within the same color layer are counted as one object. Lastly, we need to extend the system so that the combining process can automatically run.

\section{References}

[1] Rayan Abdullah and Roger Hubner, "SIGN, ICON and PICTOGRAM," R.I.C, 2006.

[2] Aisaku Murakoshi, "World wide visual symbols," Sekai Bunka Publishing INC, 2002.

[3] Google Goggles, http://www.google.com/mobile/goggles/\#text
[4] Hirata, K. and Katzo, T. "Query by visual example, content based image retrieval," in Advances in Database Technology-EDBT'92, Vol. 508, Pirotte, A., Delobel, C. and Gottlob, G., Eds., 1992.

[5] Niblack, W. et al., "The QBIC project: Quering images by content using color, texture and shape," in Proc. SPIE Storage and Retrieval for Image and Video Data Bases, pp. 172-187, 1994.

[6] David A. Forsyth, Jean Ponce: "Computer Vision: A Modern Approach, "Prentice Hall, 2002.

[7] Chang, S.K., "Image Database Systems," Handbook of Pattern Recognition and Image Processing, Young, T. Y. and Fu, K. S. (eds), pp. 371-393, Academic Press, 1986.

[8] R. Datta, et al. 'Image Retrieval: Ideas, Influences, and Trends of the New Age," ACM Computing Surveys, vol. 40, no. 2, article 5, 60 pages, 2008.

[9] Rui, Y., Huang, T. S. and Mehrotra, S., "Contentbased image retrieval with relevance feedback in Mars," in Proc. IEEE Conf. Image Processing, pp. 815-818, 1997.

[10] Rocchio JJ, "Relevance Feedback in Information Retrieval. "In: The SMART Retrieval System, 1971, pp. 313-323, Prentice Hall.

[11] Yasushi Kiyoki, Takashi Kitagawa and Takanari Hayama: "A meta-database system for semantic image search by a mathematical model of meaning," ACM SIGMOD Record, Vol. 23 Issue 4, December 1994.

[12] Xing Chen and Yasushi Kiyoki, "A Visual and Semantic Image Retrieval Method Based on Similarity Computing with Query-Context Recognition," Information Modeling and Knowledge Bases. Vol. XVIII, pp. 245-252, May 2007.

[13] Yasuhiro Hayashi, Yasushi Kiyoki and Xing Chen: "An Image-Query Creation Method for Expressing User's Intentions by Combining Multiple Images," Information Modeling and Knowledge Bases, IOS Press, Vol. XXI, pp.188-207, 2010.

[14] Yasuhiro Hayashi, Yasushi Kiyoki and Xing Chen: "A Combined Image-Query Creation Method for Expressing User's Intentions with Shape and Color Features in Multiple Digital Images," Information Modeling and Knowledge Bases, IOS Press, Vol. XXII, pp.258-277, 2011. 
[15] Michael J. Swain, Dana H. Ballard: "Color Indexing," International Journal of Computer vision, Vol. 7, No.1, pp. 11-32, 1991.

[16] W.H. Leung, T. Chen, "Trademark retrieval using contour-skeleton stroke classification," IEEE Int. Conf. on Multimedia and Expo., vol. 2, 2002, pp. 517-520.

[17] MATLAB, http://www.mathworks.co.jp/products/matlab/

[18] I. Valove and B. Rachev, "Retrieval by Color Features in Image Databases," Proceedings of Eighth EastEuropean Conference on Advances in Databases and Information Systems, September 2004.

[19] Pentland, A., Picard, R. W. and Sclaroff, S., "Photobook: Content-based manipulation of image database," Int. J. Comput. Vis., Vol. 18, pp. 233-254, 1996.

[20] Ma, W.-Y. \& Manjunath, B. S. "NeTra: A Toolbox for Navigating Large Image Databases," Multimedia Systems, 1999, 7, 184-198.

[21] Siggelkow, S.; Schael, M. \& Burkhardt, H. SIMBA Search IMages By Appearance in Pattern Recognition, Proc. of 23rd DAGM Symposium, B. Radig and S. Florczyk, Eds. Sept. 2001, number 2191 in LNCS Pattern Recognition, Springer Verlag, 2001, 9-17.

[22] James Hays and Alexei A Efros, "Scene Completion Using Millions of Photographs, " ACM Transactions on Graphics (SIGGRAPH 2007), vol. 26, number 3, 2007.

[23] James Z. Wang, Jia Li, Gio Wiederhold, "SIMPLIcity: Semantics-sensitive Integrated Matching for Picture Llbraries," IEEE Trans. on Pattern Analysis and Machine Intelligence, vol 23, no.9, pp. 947-963, 2001.A.N. Author, Book Title, Publisher Name, Publisher Location, 1995. 